\title{
Determinants of stillbirths occurred in health facilities in Zambezia province, Mozambique (2013-2014)
}

Germano Pires 1

Maria Rosa 2

Minó Zangarote 3

Sérgio Chicumbe 4

\author{
1,3,4 Grupo de pesquisa em Sistemas de Saúde. Instituto Nacional de Saúde. Ministério da Saúde. Av. Eduardo Mondlane \# 1008, Maputo, Moçambique. \\ E-mail: germapi@hotmail.com
}

2 Direç̧ão Provincial de Saúde da Zambézia.

\begin{abstract}
Objectives: to identify the determinants of stillbirths in Zambezia province, Mozambique.

Methods: a retrospective cross-sectional ecological study was carried out in 2013-2014 by using perinatal indicators captured by the health information system in Zambezia. Sequentially perinatal care indicators, bivariate analysis and multiple adjusted regression at a 5\% significance level with possible explainable variables of stillbirths were described.

Results: a median proportion of stillbirths was $1.6 \%$, low birth weight and preterm birth and obstetric complications were $4.9 \%, 1.9 \%$ and $4.1 \%$, respectively. The bivariate analysis demonstrated association of stillbirths with anemia $(p=0.043)$, antepartum hemorrhage $(p=0.009)$, dystocic delivery $(p<0.001)$, obstructed labor $(p=0.004)$. In the analysis of multiple adjusted regression, the obstructed labor were a predictor $(\beta=0.435 ; p=0.03)$ to stillbirths

Conclusions: the most important factor associated to stillbirths in health facilities in Zambezia province in 2013-2014 was the obstructed labor. The strengthening of diagnostic analysis and the attempt to handle obstetric complications is still a priority in Zambezia, in being able to decrease the avoidable perinatal deaths.
\end{abstract}

Key words Stillbirth, Determinants, Zambezia province, Mozambique 


\section{Introduction}

In Mozambique, the fetal mortality rate is determined by the number of fetal deaths that occurred on the $28^{\text {th }}$ week of gestation or the fetuses with an equal weight or greater than $1500 \mathrm{~g}$ per one thousand total live births in a population residing in a given geographical space, in the considerate year. This rate is one of the main indicators of the quality in the health services that are provided during pregnancy and childbirth. ${ }^{1}$

The number of stillbirths is still considerable. The estimated number of stillbirths in 2009 was 2.64 million, relatively less when compared to 3.03 million in 1995, observing a downward trend. The rate of stillbirths decreased from 22.1 per thousand births in 1995 to 18.9 per thousand in 2009 , however, the largest proportion, approximately $72.2 \%$, occurred in South Asia and in the SubSaharan Africa.2,3 Despite the decreased trend, the number of stillbirths remains unacceptably high.

The perinatal obstetric complications, maternal infectious diseases, including syphilis and the infection of human immunodeficiency virus (HIV) are pointed out as determinants more proximally to the occurrence of stillbirth, 4,5 although screening and prophylaxis of infectious diseases and other prenatal consultations are performed. Emphasizing that the wide expansion of screening in the past decade was mostly in Africa. 6 Other determinants of distal stillbirths can be summarized in socioeconomic inequalities and the assistance to prenatal care, and the specific needs of vulnerable groups such as teenage pregnancy. 7,8

In Mozambique, the rate of stillbirths remains as one of the highest in the world, although there are initiatives to reduce avoidable stillbirths. The stillbirths evaluation committees are established to various administrative levels of national health service and the quality of perinatal care which have received investments in order to improve, in being the most visible and initiatively becoming the "maternity model". ${ }^{9}$ Due to all the efforts there has been a substantial overall decrease in the rate of stillbirths in Mozambique of 8/1,000 viable pregnancies in the period of 2003-2011, and in Zambezia province, this rate was even lower $5 / 1,000$ viable pregnancies at the same period.9-11 The reduction in the rate of stillbirths is one of the utmost priority for health authorities. It is important to do follow-ups on the determinants of stillborn infants in order to inform the necessary efforts to achieve improvements in this and in other perinatal health indicators, in a context of scarce resources hence; this is the focus of this study.

\section{Methods}

A retrospective cross-sectional ecological study was conducted by using the outcomes of perinatal health indicators, captured by the health information system in Zambezia province.

Zambezia is a province located in the central region of Mozambique, about 1,600 km from the capital of the country, with a population of 4,327,163 inhabitants, of which $2,238,278$ are women and $48.7 \%$ are in reproductive age, with a fertility rate of approximately six children per woman. 12

The analysis unit was the perinatal health indicators routine, covering all the health units in Zambezia province in assisting births in the period of January 2013 to December 2014. The health information system in Zambezia covers all the health units in the province and the data were collected in a routine and prospective form. The instruments for the data collection in the maternity are standardized throughout the country, constituting in: demands of file books and follow-ups on patients at the maternity; clinical obstetrics files containing flowcharts on partogram according to the standards of the World Health Organization (WHO); monthly summary forms resulting on care and perinatal health indicators. 13 The monthly summary forms aggregating the indicators of interest in this present study and, are scanned.

The quality and completeness are primarily verified by a committee of health technicians who provide perinatal care and at the end, the statistic technicians at the health unit, and then after the district and provincial. The data passes through multiple verifications at different levels, and finally the final verification in the provincial capital with eventual corrections in the retrogressive system.

The obstetric diagnoses considered in the system of record are syndromic, because, as being a standardized information system for the whole country, it should ensure appropriate diagnosis and recording by a less qualified healthcare professional. The International Classification of Diseases - the $10^{\text {th }}$ Review (CID-10) is only used in relatively specialized health units, whereas, they are the minority.

The Ministry of Health of Mozambique, recognizing the challenge of data completeness and quality, hired specialists in the field of information system from private services to guarantee by means the intense activity of formation, maintenance and verification of quality and the functionality of the information system of perinatal health indicators in 
the entire country. 13 The data bases managed and maintained by this entity are provided on Microsoft Excel format.

The indicator of interest in this study was the prevalence of stillbirths. Explanatory variables were indicators of maternal health and childbirth care, registered in the information system, including anemia, malaria, prophylaxis for HIV, eclampsia, antepartum hemorrhage, dystocic delivery (mal fetal presentation), obstructed labor syndrome, the use of partogram in monitoring births and access to a referential health care unit (with the capacity of surgical procedures in obstetrics).

The Pearson correlation analysis to determine the bivariate association and the linear regression of exploring stillbirth predictors from a statistical package, the IBM PAWS (SPSS) version 23, a significant level of $5 \%$. The variables which had $p<0.05$ in the bivariate analysis were included in the adjusted multiple linear regression model.

This study was approved by the Institutional Bioethics Health Committee of the National Institute of Health (reference 062/CIBS-INS/2014).

\section{Results}

In this study period, 265,782 births occurred in health units of Zambezia province. The median proportion of stillbirths was $1.6 \%$ (interquartile interval - IIQ 1\%). The median proportion of low birth weight and preterm newborns were $4.9 \%$ (IIQ $2.8 \%$ ) and $1.9 \%$ (IIQ $1 \%$ ) respectively, and the median prevalence of obstetric complications was of $4.1 \%$ (IIQ 2.1\%) (Table 1).

The occurrence of stillborns was significantly correlated with the indicators of anemia (Pearson's coefficient $0.429 ; p=0.043$ ), antepartum hemorrhage (Pearson's coefficient 0.56; $p=0.009$ ), dystocic delivery (Pearson's coefficient 0.85; $p<0.001$ ), obstructed labor (Pearson's coefficient correlation $0.62 ; p=0.004)$. There was no significant correlation of stillborns with other perinatal medical conditions, such as malaria, HIV, eclampsia and indicators of quality approximation of childbirth monitoring and access to obstetric care, especially in the correct use of the partogram and a district of a referential health unit (Table 2). In the multiple adjusted linear regression model, the obstructed labor was the only predictor $(B=0.435 ; p=0.03)$ of stillborns (Table 3$)$.

\section{Discussion}

This study contributes to improve the use of data routine in the follow-up on the conditions and the results in the health care in Mozambique. The stillbirth rates in Zambezia province, Mozambique is

\section{Table 1}

Median proportion of syndromes and perinatal indicators of services captured by the health information system in the province of Zambezia, Mozambique, 2013-2014.

\begin{tabular}{lcc}
\hline Indicators & Median (\%) & IIQ (\%) \\
& $\mathrm{N=265,782}$ & 1.00 \\
\hline Stillbirths & 1.60 & 1.00 \\
Prematurity [GA (28w - 36w6d)] & 1.90 & 2.80 \\
Low weight at birth & 4.90 & 1.10 \\
Malaria & 1.10 & 0.50 \\
Anemia & 0.50 & 8.00 \\
HIV 0.60 & 1.50 & 1.20 \\
Prophylaxis HIV - ARV & 4.70 & 0.20 \\
Eclampsia & 0.40 & 0.50 \\
Antepartum hemorrhage & 0.50 & 2.80 \\
Postpartum Hemorrhage & 0.80 & 0.80 \\
Dystocic delivery & 1.20 & 2.10 \\
Obstructed labor* & 0.90 & 22.40 \\
Direct obstetric complications & 4.10 & 68.70 \\
Use of partogram & & \\
\hline
\end{tabular}

$\mathrm{GA}=$ gestational age; $\mathrm{w}=$ weeks; $\mathrm{d}=$ days; HIV = human immunodeficiency virus; $\mathrm{ARV}=$ antiretroviral; $\| \mathrm{Q}=$ interquartile interval; * dystocic delivery were excluded. 
Correlation of stillbirths with indicators of syndromes and perinatal care obtained from the surveillance system of health of the province of Zambezia, Mozambique, 2013-2014.

\begin{tabular}{|c|c|c|}
\hline & \multicolumn{2}{|c|}{ Stillbirths $(\mathrm{N}=5,519)$} \\
\hline & Pearson correlation ( $r$ ) & $p$ \\
\hline Anemia & 0.429 & 0.043 \\
\hline Malaria & -0.078 & 0.382 \\
\hline Prophylaxis HIV - ARV & 0.355 & 0.081 \\
\hline Eclampsia & -0.141 & 0.295 \\
\hline Antepartum hemorrhage & 0.563 & 0.009 \\
\hline Dystocic delivery & 0.849 & $<0.001$ \\
\hline Obstructed labor & 0.618 & 0.004 \\
\hline Use of partogram & 0.142 & 0.293 \\
\hline District with CONEmC & 0.412 & 0.05 \\
\hline
\end{tabular}

$\mathrm{HIV}=$ viruses of immunodeficiency acquired; $\mathrm{ARV}=$ antiretroviral; CONEmC = obstetric care and neonatal emergency.

Table 3

Adjusted Regression for exploration of stillbirths predictors occurred between 2013-2014 in the province of Zambezia, Mozambique.

\begin{tabular}{|c|c|c|c|c|c|}
\hline \multirow[t]{2}{*}{ Model } & \multicolumn{2}{|c|}{ Coefficients } & \multirow[t]{2}{*}{$p$} & \multicolumn{2}{|c|}{$\begin{array}{c}\mathrm{Cl} 95 \% \\
\boldsymbol{\beta}\end{array}$} \\
\hline & $\beta$ & S tandard E rror & & minimum & maximum \\
\hline (Constant) & 0.225 & 0.427 & 0.609 & -0.706 & 1.155 \\
\hline Anemia & 0.37 & 0.341 & 0.299 & -0.373 & 1.113 \\
\hline Antepartum Hemorrhage & 1.334 & 0.648 & 0.062 & -0.077 & 2.745 \\
\hline Dystocic delivery & 0.108 & 0.057 & 0.085 & -0.017 & 0.233 \\
\hline Obstructed delivery* & 0.435 & 0.176 & 0.030 & 0.05 & 0.819 \\
\hline
\end{tabular}

Dependent variable: stillbirths; * Obstructed labor is a diagnosis syndromic intrapartum which excludes dystocic delivery.

substantial, considering the verified rate (close to $2 \%$ ) in a context of high number of births. However the proportion of stillbirths in Zambezia is relatively low if compared to the proportions of other provinces in the country at the same period of the study, but it is high relatively to the desired goals. Similar studies conducted in other countries, estimated that in 2015 there were approximately 1.3 million stillbirths, equivalent to 18.4 per thousand births, even in a context in which two-thirds of all childbirths already occurred in the health facilities of low-income countries, as is the case of Mozambique. This suggests that the need to improve the quality of the health care in the perinatal period to maximize the well-being of the mother and the fetus is still a challenge to overcome, a fact that the results of this study corroborates. $2,14,15$

The proportion of low birth weight of the newborn is relevant in this analysis, because the low birth weight reduces, to some extent, the survival of the newborns. 16 In addition to this indice, the analysis indicated substantially higher proportions in relation to prematurity, the need of prophylaxis for $\mathrm{HIV}$ and direct obstetric complications, indicating once again that the current needs for improving perinatal health are still multiple in the studied context. 
The determinant factors in the bivariate and multivariate analyzes are chronically implicated as causes of poor outcomes of childbirths, and the results suggest that in Zambezia province, and possibly in Mozambique in general, the main causes of stillbirths remains without great alterations, although many interventions are focused on perinatal health, since 1990, for example the initiatives of safe motherhood, implantation of discreet committee analysis of perinatal deaths as a strategy to improve the quality, the impulse of the aims in developing the millennium in the investment for maternal and child health and, more recently, programs of maternity and perinatal care, although it is noticeable in some remote areas from the country, with poor adherence of prenatal consultations for pregnant women. The factors identified in this study and efforts to improve the ability to detect all the complications associated to stillbirths were also described in other publications. 17,18 The results obtained from other countries, also with the aim of determining causes and the frequency of stillbirths showed that the onset of delayed prenatal consultations and the fact of being primigravida, also predict the occurrence of the stillbirth. 17,19,20 Although these factors are captured

\section{References}

1. Brazil. Ministério da Saúde. Secretaria de Vigilância em Saúde. Manual de vigilância do óbito infantil e fetal e do Comitê de Prevenção do Óbito Infantil e Fetal. (2009). Disponível em: http://svs.aids.gov.br/download/manuais/ manual_infantil_fetal03_fim2_1.pdf

2. Cousens S, Blencowe H, Stanton C, Chou D, Ahmed S, Steinhardt L, Creanga AA, Tunçalp O, Balsara ZP, Gupta S, Say L, Lawn JE. National, regional, and worldwide estimates of stillbirth rates in 2009 with trends since 1995: systematic analysis. Lancet. 2011; 377 (9774): 1319-30.

3. Blencowe H, Cousens S, Jassir FB, Say L, Chou D, Mathers C, Hogan D, Shiekh S, Qureshi ZU, You D, Lawn JE; Lancet Stillbirth Epidemiology Investigator Group. National, regional, and worldwide estimates of stillbirth rates in 2015, with trends from 2000: a systematic analysis. Lancet Glob Health. 2016; 4 (2): e98-e108.

4. Mullick S. Sexually transmitted infections in pregnancy: prevalence, impact on pregnancy outcomes, and approach to treatment in developing countries. Sex Transm Infect. 2005; 81: 294-302

5. Aminu M, Unkels R, Mdegela M, Utz B, Adaji S, van den Broek N. Causes of and factors associated with stillbirth in low- and middle-income countries: a systematic literature review. BJOG Int J Obstet Gynaecol. 2014; 121 (Supl. 4) 141-53

6. Gloyd S, Montoya P, Floriano F, Chadreque MC, Pfeiffer J, Gimbel-Sherr K. Scaling up antenatal syphilis screening in Mozambique: transforming policy to action. Sex Transm from primary sources and were not identified in the present study, since the study was based on indicators of the information system routine which excludes such information. The results of this study, despite the limitations of not obtaining all the possible variables of the system for the adjusted analysis, inherent fact and expected ecological studies based on aggregated data routine, corroborating results from another study on determinants of stillbirths, performed in another province in Mozambique, Tete, central region of the country with primary data collection and which identified obstetric complications as the main cause of stillbirths, ${ }^{11}$ although these studies have a quiet different methodological approach.

Thus, the stillbirth rates in the province of Zambezia has been significantly determined by the rate of the obstructed labor syndrome, suggesting that the health system still needs to strengthen its ability to diagnosis, have sensitivity and manage timely of acute complications in the progression of the labor. To a greater extent, these acute complications can be solved, by which it is licit that stillbirths are substantially avoidable in the studied context.
Dis. 2007; 34 (Supl. 7): S31-6.

7. Almeida MF, Alencar GP, Novaes HMD, França Jr I, Siqueira AAF, Campbell OMR, Schoeps D, Rodrigues LC. Fatores de risco para mortes fetais anteparto no Município de São Paulo, Brasil. Rev Saúde Pública. 2007; 41 (1): 3543.

8. Fonseca SC, Coutinho ESF. Perinatal mortality research in Brazil: review of methodology and results. Cad Saúde Pública. 2004; 20 (Supl. 1): S7-19.

9. Instituto Nacional de Estatística-Ministério da Saúde, Moçambique. Inquérito Demográfico da Saúde. 430 (2011).

10. Inquérito Demográfico de Saúde. 374 (Instituto Nacional de Estatística-Ministério da Saúde, Moçambique, 2003).

11. Geelhoed D, Stokx J, Mariano X, Mosse Lázaro C, Roelens $\mathrm{K}$. Risk factors for stillbirths in Tete, Mozambique. Int $\mathrm{J}$ Gynaecol Obstet. 2015; 130 (2):148-52.

12. Institito Nacional de Estatística, Moçambique. Indicadores sócio demográficos da província da Zambézia; 2011.

13. Malaria consortium. Mapping of the health information system in Mozambique and identification of its constraints; 2010.

14. Joy E Lawn, Hannah Blencowe, Peter Waiswa, Agbessi Amouzou, Colin Mathers, Dan Hogan, Vicki Flenady, J Frederik Frøen, Zeshan U Qureshi, Claire Calderwood, Suhail Shiekh, Fiorella Bianchi Jassir, Danzhen You, Elizabeth M McClure, Matthews Mathai, Simon Cousens, for The Lancet Ending Preventable Stillbirths Series study 
group* with The Lancet Stillbirth Epidemiology \& investigator group*. Stillbirths: rates, risk factors and acceleration towards 2030. Lancet. 2016; 387: 587-603.

15. Goldenberg RL, Saleem S, Pasha O, Harrison MS, Mcclure EM. Reducing stillbirths in low-income countries. Acta Obstet Gynecol Scand. 2016; 95: 135-43.

16. Silva CA, Brusamarello S, Cardoso FGC, Adamczyk NF, Neto FR. Desenvolvimento de prematuros com baixo peso ao nascer nos primeiros dois anos de vida. Rev Paul Pediatr. 2011; 29: 328-35.

17. Pedro Filho F, Germano MCM. Determinantes de natimortalidade em um serviço municipal de assistência hospitalar. Rev Bras Promoção Saúde. 2004; 17: 187-92.

18. Flenady V, Wojcieszek AM, Middleton P, Ellwood D, Erwich JJ, Coory M, Khong TY, Silver RM, Smith GC, Boyle FM, Lawn JE, Blencowe H, Leisher SH, Gross MM, Horey D, Farrales L, Bloomfield F, McCowan L, Brown SJ, Joseph KS, Zeitlin J, Reinebrant HE, Ravaldi C, Vannacci A, Cassidy J, Cassidy P, Farquhar C, Wallace E, Siassakos D, Heazell AE, Storey C, Sadler L, Petersen S, Frøen JF, Goldenberg RL; Lancet Ending Preventable Stillbirths study group; Lancet Stillbirths In High-Income Countries Investigator Group. Ending preventable stillbirths 4 Stillbirths: recall to action in high-income countries. Lancet. 2016; 387(10019): 691-702.
19. McPherson E. Recurrence of stillbirth and second trimester pregnancy loss. Am J Med Genet A. 2016; 170A (5): 117480 .

20. Mustufa MA, Kulsoom S, Sameen I, Moorani KN, Memon AA, Korejo R. Frequency of Stillbirths in a Tertiary Care Hospital, Karachi. Pak J Med Sci. 2016; 32 (1): 91-4.

Received on May 20, 2016

Final version presented on September 15, 2016

Approved on November 4, 2016 